\title{
Nano-scale Surface Wrinkling in Chiral Liquid Crystals and Plant-based Plywoods
}

\author{
Pardis Rofouie, ${ }^{\mathrm{a}}$ Damiano Pasini ${ }^{\mathrm{b}}$ and Alejandro D. Rey ${ }^{* \mathrm{a}}$ \\ ${ }^{a}$ Department of Chemical Engineering, McGill University,3610 University street, Montreal, Quebec, \\ Canada, H3A 2B2, E-mail: alejandro.rey@mcgill.ca; Fax: +1 514 398-6678; Tel: +1 514 398-4196 \\ ${ }^{b}$ Department of Mechanical Engineering, McGill University, Montreal, Quebec, Canada, H3A 2K6

\begin{abstract}
We present theoretical scaling and computational analysis of nano-structured free surfaces formed in chiral liquid crystals (LC) and plant-based twisted plywoods. A nemato-capillary model is used to derive a generalized equation that governs the shape of cholesteric free surfaces. It is shown that the shape equation includes three distinct contributions to the capillary pressure: area dilation, area rotation, and director curvature. To analyse the periodic relief in plywood surfaces, these three pressure contributions and corresponding surface energies are systematically investigated. It is found that for weak homeotropic surface anchoring the nano-wrinkling is driven by the director curvature pressure mechanism. Consequently, the model predicts that for a planar surface with a uniform tangential helix vector no surface wrinkling can be observed since the director curvature pressure is zero. Scaling is used to derive the explicit relation between the wrinkling's amplitude to the wave-length ratio as a function of the anisotropic surface tension, which is then validated with experimental values. These new findings can be used to characterize plant-based twisted plywoods as well as to inspire the design of biomimetic chiro-optical devices.
\end{abstract}

\section{Introduction}

Biological liquid crystals (BLCs) are anisotropic viscoelastic materials exhibiting long range orientational order and partial positional order. ${ }^{1}$ The liquid crystalline phase and topological defects in biological analogues are usually those of chiral nematics (cholesteric) and hence they are referred to as biological helicoidal plywoods ${ }^{2,3}$, also known as the Bouligand architecture. ${ }^{4}$ Helicoidal plywoods are found in many biological materials, such as DNA in human cells, ${ }^{5}$ cellulose in plant cell walls, ${ }^{6}$ chitin in arthropods cuticles, ${ }^{2}$ and collagen in human compact bones. ${ }^{7}$ BLCs are functional materials that display several unique properties ${ }^{8}$ such as nano-scale surface wrinkling observed in LC DNA, ${ }^{9}$ cellulose, ${ }^{10}$ and collagen. ${ }^{11}$ Cholesteric films of concentrated collagen solutions exhibit periodic undulations at the free surface with an amplitude of the order of 150 $\mathrm{nm}$, and a periodicity of the order of $3.5 \mu \mathrm{m} .{ }^{11}$ Undulations of similar scales are also observed in silk gland ducts of golden orb-web spider Nephilaclavipes, ${ }^{12}$ the exoskeleton of the beetle Chrysinagloriosa,${ }^{13}$ and cellulosic materials. ${ }^{10}$ These nano-scale structures that formed spontaneously on the free surface of BLC are responsible for their particular optical responses resulting in structural colors, observed in beetles, ${ }^{13}$ mollusk shells, ${ }^{14}$ and some plants. ${ }^{15}$ The study of the formation of these surface undulations is fundamental in understanding structural color in nature and can inspire the design of optical devices with novel functionalities. ${ }^{16}$

Photonic structures in many floral plants are associated with the shape and the anatomy of the plant surface topography. It has been reported that certain floral plant species, such as Hibiscus trionum and Tulipakaufmanniana petals, use ordered striation or ridges to obtain iridescence with a striking metallic appearance. ${ }^{17}$ Although the formation of these micro- and nanostructures during the development of the petals is not well-understood yet, it is believed that cellulosic CLCs are responsible for plant surface undulations and iridescent colors. In the preparation of a lyotropic cholesteric mesophase, Werbowyi and Gray discovered that concentrated aqueous solutions of (hydroxypropyl) cellulose (HPC) displayed iridescent colors that changed with concentration and viewing angle. ${ }^{18}$ Efforts have been made to trap the CLC structure in solid films to create colored iridescent films. ${ }^{19}$ Fernandes et al. fabricated iridescent solid cellulosic films with tunable mechanical and structural color properties, which mimic the structures found in the surface of the "Queen of the Night" tulip petals, which display periodic striation of about $1.5 \mu \mathrm{m}$, responsible for petal iridescence..$^{20}$ They indicated that the formation and periodicity of the surface structure are governed by the CLC structure.

Although, the chiral surface structures are extensively studied by microscopy methods including atomic force microscopy (AFM) ${ }^{21}$ the complementary theoretical analysis of CLC surface wrinkling is rarely studied. The formation of surface nanostructures in CLC interfaces is a complex phenomenon involving interfacial tension, surface anchoring energy, and LC Frank elasticity ${ }^{8}$ that requires integrated multi-scale modelling of bulk and surface. ${ }^{22}$ In a study of cholesteric liquid crystal free surface, Meister et al described the periodic relief of a cholesteric liquid crystal interface by minimisation of surface free energy composed of the anchoring energy and the surface tension. ${ }^{23}$ They found that for relatively strong and finite anchoring, the surface deformation energy arises due to director surface gradient and elastic constants. ${ }^{23 a}$ The director distributions in the distorted region coupled with anchoring energy create nano-scale undulations in the free surface.

The plant cell wall is a multifunctional viscoelastic structure made of cellulose microfibrills (CMFs) coated with hemicelluloses and embedded in a matrix of lignin/pectin. ${ }^{24}$ Plant cell wall includes a primary cell wall (p) laid down during growth on the outside and three secondary cell walls $\left(\mathrm{S}_{1}, \mathrm{~S}_{2}, \mathrm{~S}_{3}\right)$ that formed when the cell has reached its final size and shape ${ }^{25}$ Although the primary and secondary wall layers differ in the specific chemical composition (cellulose and hemicellulose contents are greater in secondary walls than primary walls) and structural organization (CMFs in primary layers are organized in a loose interwoven texture, while are well-oriented in secondary layers). Overall, CMFs in the polysaccharide matrix are oriented in strategic directions to form twisted plywood architecture for optimal mechanical efficiency. The proof that plant cell wall are formed through a liquid crystalline self-assembly process is the presence of the microstructure, textures and defect patterns observed in secondary cell wall of some plan species. ${ }^{8,26}$ The plant cell wall helicoidal plywoods can be characterized by the helix axis $\mathbf{H}$, the pitch length $\mathrm{p}_{0}$, which is the distance through which the fibers undergo a $2 \pi$ 
rotation and handedness (sign of $\mathrm{p}_{0}$ ), and the average fiber orientation $\mathbf{n}$ which is normal to $\mathbf{H}$ (see Fig.1).

In a recent communication ${ }^{27}$ we briefly presented the main mechanism that operate in chiral capillarity using a plant-based plywood as a model material system. In this paper, we present a comprehensively analysis of the nano-scale structures observed in chiral surfaces in full detail and predict the response of the surface structure to chirality and anisotropic tension changes. We restrict our attention to the case in which the helix axis remains at all times parallel to the surface; other complex structures arising when the helix axis is tilted are beyond the scope of this paper. Focusing on the cellulosic CLCs material model, we use the generalized shape equation for anisotropic interfaces using the Cahn-Hoffman capillarity vector developed for $\mathrm{LCs}^{28}$ and the well-known RapiniPapoular anchoring energy ${ }^{29}$ for the anisotropic part of the interfacial tension, to analyze periodic nano-wrinkling in plant-based plywood free surfaces. The objective of this paper is to identify the key mechanisms that induce and resist nano-wrinkling in CLC, and to formulate nano-wrinkling scaling laws of biomimetic utility for the design of optical gratings and as a tool to characterize plant-based plywoods.

The organization of this paper is as follows. Section 2 presents the governing nemato-capillary shape equation expressing the coupling mechanism between the surface geometry and cellulose fiber orientation for CLC/air interface in rectangular (x,y,z) coordinates. The capillary shape equation is derived and described in terms of three capillary pressures. Appendix A presents the details of the derivation of the Cahn-Hoffman capillary vector thermodynamics for CLC interfaces. Appendix B derives the generic conditions under which the director curvature pressure is zero. Appendix $\mathrm{C}$ formulates the capillay shape equation for the splay-bend director field relevant to nao-wrinkling. Section 3 analyses the effect of model parameters on the surface profile. The leading mechanism controlling chiral wrinkling is determined and the generic sufficient condition that results in flat and non-flat surfaces is derived. Furthermore, the surface energies associated with the CLC interface are presented and discussed. Finally, based on a standard order of magnitude analysis, a scaling formula expressing surface profile amplitude as a function of model parameters is presented and validated with a number of experimental biological CLC surface undulations and with numerical results. Section 5 presents the conclusions.

\section{Capillary shape equation}

We assume that the surface undulations in plant cell walls are formed through modulation in surface energy at the anisotropic-air interface and are influenced by the macroscopic chirality of the cellulose fibers. The coupling mechanism between the surface geometry and cellulose fiber orientation can be demonstrated through the shape equation. In this section, the capillarity shape equation using the capillary vector $\xi^{30}$ is presented for the CLC free interfaces in rectangular $(x, y, z)$ coordinates and the resulting surface pressures are formulated.

For isotropic interfaces, the capillary pressure, $p_{c}$, based on the well-known Young-Laplace equation, is proportional to the surface tension $\gamma$ and vanishes for plane surfaces $\left(\nabla_{s} \cdot \mathbf{k}=0\right):{ }^{31}$

$$
\mathrm{p}_{\mathrm{C}}=\nabla_{\mathrm{S}} \cdot \mathbf{k} \gamma
$$

where $\nabla_{s}=\nabla_{s} \mathbf{k}$ is the surface gradient, $\mathbf{I}_{\mathbf{s}}=\mathbf{I}-\mathbf{k k}$ is the $2 \times 2$ unit surface dyadic, and $\mathbf{k}$ is the surface unit normal. For a cholesteric liquid crystal (CLC) surface, however, the anisotropic surface tension contributes additional modes to the capillary pressure. The interfacial surface tension $\gamma$ for anisotropic surfaces is a function of the surface unit normal $\mathbf{k}$ and the director $\mathbf{n}: \gamma(\mathbf{k}, \mathbf{n})$ and is given by Rapini and Papoular: ${ }^{29}$

$$
\gamma(\mathbf{n}, \mathbf{k})=\gamma_{0}+\gamma_{\text {aniso }}(\mathbf{n}, \mathbf{k}) ; \gamma_{\text {aniso }}(\mathbf{n}, \mathbf{k})=\frac{\mathrm{W}}{2} \gamma_{\text {aniso }}(\mathbf{n} . \mathbf{k})^{2}
$$

where $\gamma_{0}$ is the isotropic contribution, $\gamma_{\text {aniso }}$ is the anisotropic anchoring energy contribution, and $\mathrm{W}$ is the anchoring energy coefficient. The anisotropic surface tension appears as the property that renormalizes the isotropic component of the interfacial tension and promotes the rotation of the interface. The anchoring energy contribution is associated with the director deviations from its preferred orientation due to bulk distortions or external fields. The preferred orientation or easy axis corresponding to eqn (2) can be parallel to the unit normal $\mathbf{k}$ (homeotropic), perpendicular to the unit normal $\mathbf{k}$ (planar). In the present paper, we restrict the discussion to homeotropic anchoring $(\mathrm{W}<0)$, because for planar surface anchoring $(\mathrm{W}>0, \mathbf{n . k}=0)$ the helicoidal structure, in which helix axis is perpendicular to the surface, will remain undistorted as it is the most stable and lowest energy state $;^{32}$ the undistorted helix results in a flat surface. $^{23 a}$

As the nematic director in CLCs continuously rotates along the helical axis, the helix structures (helixes perpendicular $(\mathbf{H . k}=\mathbf{0})$ and parallel $(\mathbf{H} . \mathbf{k}=1)$ to the surface) for strong homeotropic anchoring $(\mathrm{W}<0)$ is not fully compatible with any uniform aligning surface ${ }^{33} \mathrm{As}$ the result, the average orientational order is disrupted due the frustration that leads to sub-surface defect nucleation, which can be resolved by changing the interface shape. The appearance of inclusions and formation of defects in the bulk can change the director orientation in the CLC and results in a periodicity at the free surface whose wave length can vary from half helical pitch $\mathrm{p}_{0} / 2$ to $\mathrm{p}_{0}$ or even greater. ${ }^{21 b, 34}$ Here we assume that the pitch of the distorted region is equal to the bulk $\mathrm{p}_{0}$. The effect of $\mathbf{n}(\mathrm{x})$ on surface relief of two CLC structures is shown in Fig.1. The distorted surface layer can be generated by either vertical or tangential helixes in the bulk (note that only a horizontal helix alignment $\mathbf{H}$ is presented in Fig.1).

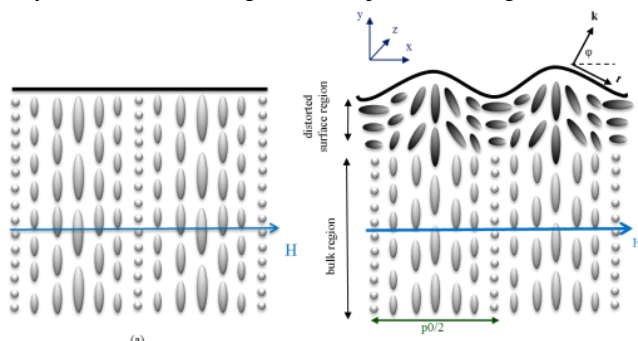

Figure.1 Schematic of a cholesteric liquid crystal (plywood architecture) and surface structures. $\mathbf{H}$ is the helix unit vector, and $\mathrm{p}_{0}$ is the pitch. (a) The surface director has an ideal cholesteric twist and the surface is flat. (b) Bend and splay orientation distortions for $\mathrm{W}<0$ create surface undulations. Adapted from ref $23 \mathrm{a}$.

The Cahn-Hoffman capillary vector $\xi^{30}$ is the fundamental quantity that provides a direct and clear way to explain the role of anisotropy in capillary pressure and its role in surface shape determination. The capillary vector $\xi$ takes into account the changes in surface energy due to surface dilation (change in area) and surface rotation (change in unit normal $\mathbf{k}$ ) in one single vectorial quantity. In this section, the key formulations of the capillary vector thermodynamics are presented. Appendix A gives the details of the derivation of the Cahn-Hoffman capillary vector thermodynamics for anisotropic interfaces. ${ }^{28}$ The capillary vector $\xi$ for nematic surfaces and interfaces has two components: 


$$
\xi(\mathbf{n}, \mathbf{k})=\xi_{\perp}(\mathbf{n}, \kappa)+\xi_{\|}(\mathbf{n}, \mathbf{k})
$$$$
\boldsymbol{\xi}_{\perp}(\mathbf{n}, \mathbf{k})=\gamma \mathbf{k} ; \boldsymbol{\xi}_{\|}(\mathbf{n}, \mathbf{k})=\mathbf{I}_{\mathrm{s}} \cdot \frac{\mathrm{d} \gamma}{\mathrm{d} \mathbf{k}}
$$

The normal component $\xi_{\perp}$ describes the increase in surface energy through dilation and the tangential component $\xi_{\|}$is the change in surface energy through rotation of the unit normal. For isotropic surfaces, $\xi_{\|}=0$ and no rotational effects appear since $W=0$. It is important to note that at the free surface we have two independent fields: the director $\mathbf{n}$ and the unit normal $\mathbf{k}$. A soft surface describe the case when its shape adapts to a given director orientation, as considered in this paper.

The total capillary pressure $\mathrm{p}_{\mathrm{c}}$ is defined by $p_{c}=\nabla_{s}$. $\xi$, the divergence of the capillary vector is decomposed naturally as:

$$
\begin{aligned}
& \mathrm{p}_{\mathrm{c}}=\nabla_{\mathrm{s}} \cdot \xi=\nabla_{\mathrm{s}} \cdot\left(\xi_{\|}+\xi_{\perp}\right)
\end{aligned}
$$

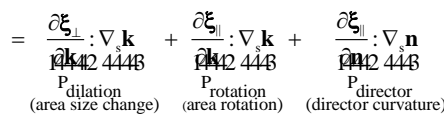

Where $P_{\text {dilation }}$ is the contribution from the normal component $\xi_{\perp}$ which is the usual Laplace pressure and $\mathrm{P}_{\text {rotation }}$ is the contribution from the tangential component $\xi_{\|}$which is the anisotropic pressure due to preferred orientation and is known as Herring's pressure. The additional contribution to the capillary pressure, $\mathrm{P}_{\text {director }}$ appears from director curvature due to orientation gradients. The capillary pressure in CLC free interfaces includes a number of novel interfacial effects: i) capillary pressure even for flat surfaces, ii) Laplace-type capillary pressure due to director orientation curvature (i.e. gradients), iii) orientation-dependent renormalization of the surface tension coefficients due to anchoring energy. ${ }^{28}$

Using eqns (2-4) we obtain the total scaled capillary pressure: ${ }^{36}$

$$
\frac{p_{c}}{\gamma_{0}}=\underbrace{\left(1-\frac{\mathrm{B}}{2}(\mathbf{n . k})^{2}+\mathrm{B}(\mathbf{n . t})^{2}\right)}_{\mathrm{P}_{\text {dilation }}+\mathrm{P}_{\text {rotation }}} \underbrace{-\mathrm{B}\left\{(\mathbf{k . n})\left(\nabla_{s} \mathbf{n}\right)+\mathbf{k n}: \nabla_{s} \mathbf{n}\right\}}_{\text {director }}
$$

where $B=W / \gamma_{0}$ is the scaled anchoring coefficient and $\kappa=d \varphi / d s$ is the surface curvature. The equation shows that the surface shape is the balance between surface tension and anchoring. The anchoring term is the driving force for surface undulations and it originates from the fact that this anisotropic surface energy is minimized when the director $\mathbf{n}$ is aligned along the preferred "easy axis". For a fixed cholesteric helical orientation, the only way to minimize this energy is to deform the interface to avoid energetically costly mismatch between the director and the easy axis. Since the director of a cholesteric is periodic, then the surface undulations are also periodic. When the director orientation deviates from the easy axis and the deviation generates gradients in surface tension, which are comparable to the characteristic kinetic energy density, the orientational-driven Marangoni flow may appear. ${ }^{37}$ In this paper we neglect this Marangoni effect and consider the shape instability as driven by elastic effects. One mechanism that may eliminate or reduce viscous effects when the helix is tangential to the surface is the high viscosity associated with permeation flow. ${ }^{38}$

For flat planar interfaces $(\kappa=0)$ the capillary pressure is driven only by director curvature:

$$
\mathrm{p}_{\mathrm{c}}=\mathrm{W}\left((\mathbf{k} . \mathbf{n})\left(\nabla_{\mathrm{s}} \mathbf{n}\right)+\mathbf{k} \cdot \mathbf{n}: \nabla_{\mathrm{s}} \mathbf{n}\right)
$$

The director curvature pressure, $\mathrm{P}_{\text {director }}$ is zero when: $\left.\left\{(\mathbf{k} . \mathbf{n})\left(\nabla_{\mathrm{s}} \cdot \mathbf{n}\right)+\mathbf{k} \cdot \mathbf{n}: \nabla_{\mathrm{s}} \mathbf{n}\right)\right\}=0$

$$
\left(\nabla_{\mathrm{s}} \mathbf{n}\right)=0 ; \mathbf{k} . \mathbf{n}: \nabla_{\mathrm{s}} \mathbf{n}=0
$$

In a rectangular $(\mathrm{x}, \mathrm{y}, \mathrm{z})$ coordinate system, to satisfy the zero director curvature pressure condition (6), we find that the director $\mathbf{n}$ must obey one of the following two conditions: 1) $\mathrm{n}_{\mathrm{x}}=0$ and $\mathrm{n}_{\mathrm{y}}=0$ or 2) $\mathrm{n}_{\mathrm{x}} \mathrm{n}_{\mathrm{y}}=$ constant (the generic conditions under which the director curvature pressure is zero are derived in Appendix B). We note that the surface director field describing a planar surface with a uniform tangential helix vector is given by $\mathbf{n}(\mathrm{x})=(0, \cos \mathrm{qx}, \sin \mathrm{qx})$, and since $n_{x}=0$, the director curvature pressure is zero and no surface wrinkling can be observed, as previosuly predcited using other approaches. ${ }^{23 a}$

To describe 1D surface undulation in a CLC, we use a rectangular coordinate frame $(\mathrm{x}, \mathrm{y}, \mathrm{z})$, where $\mathrm{x}$ is the undulation direction, and $\mathrm{y}$ the vertical axis (see Fig.1). The amplitude of the vertical undulation is $h(x)$. For a 1D texture, the surface relief is constant in the $z$ direction. The arc-length measure of the undulating surface is "s". The surface director field displaying planar splay-bend deformations is $\mathbf{n}(x)=(\cos q x, \sin q x, 0)$, where the wave-vector is $q=2 \pi / p_{0}$; we only consider a right-handed helix $(\mathrm{q}>0)$; the director angle is $\theta=\mathrm{qx}$. The surface unit normal is $\mathbf{k}(\mathrm{x})=(\cos \varphi, \sin \varphi, 0)$ where $\varphi(\mathrm{x})$ is the unknown normal angle to the surface. Using standard formulas and re-expressing $(\mathbf{k})$ as a function of $\mathrm{x}$ instead of s yields the capillary shape equation (see Appendix C):

$$
\frac{d \varphi}{d x}=\frac{p_{c}+q B \sin (\varphi)\left\{\sin ^{2}(\varphi-q x)-\cos ^{2}(\varphi-q x)\right\}}{\sin (\varphi)\left\{1-\frac{B}{2} \cos ^{2}(\varphi-q x)+B \sin ^{2}(\varphi-q x)\right.}
$$

Setting $\mathrm{p}_{\mathrm{c}}=0$ and using the above-specified splay-bend director $\mathbf{n}(\mathrm{x})$ and surface unit normal $\mathbf{k}(\mathrm{x})$ vectors gives the governing nonlinear first order ODE for the normal angle $\varphi\left(x, B, p_{0}\right)$, where $-2<\mathrm{B}<0$, $0<\mathrm{p}_{0}<100 \mu \mathrm{m}, 0<\mathrm{x}<\mathrm{L}$. This nonlinear ODE with periodic coefficients is solved using the well-known AUTO nonlinear software. ${ }^{39}$ The surface relief is then obtained from $\mathrm{h}(\mathrm{x})=\int_{0}^{\mathrm{L}} \cot \varphi \mathrm{dx}$. The boundary condition at $\mathrm{x}=0$, is $\left.\varphi\right|_{\mathrm{x}=0}=\frac{\pi}{2}$, consistent with the adopted sign of $\mathrm{B}$.

\section{Results and Discussion}

In this section we: (1) establish and quantify the effect of anchoring (B) and chirality $\left(\mathrm{p}_{0}\right)$ on the normal angle $\varphi\left(\mathrm{x}, \mathrm{B}, \mathrm{p}_{0}\right)$ and on the amplitude profile $\mathrm{h}\left(\mathrm{x}, \mathrm{B}, \mathrm{p}_{0}\right)$, (2) use a pressure-energy analysis to characterize wrinkling, and (3) formulate and validate scaling relations for $\mathrm{h}_{\max }$ as a function of $\mathrm{B}$ and $\mathrm{p}_{0}$

\subsection{Free surface profile}

The generic features of the amplitude profile $h(x)$, its maximum value $\mathrm{h}_{\max }$, and its periodicity $\mathrm{h}(\mathrm{x})=\mathrm{h}(\mathrm{x}+\lambda)$ are the three relevant outputs of the model. The two significant parameters influencing $h(x)$ are the scaled anchoring coefficient $B$ and the micron scale length of the pitch $\mathrm{p}_{0}$. For the nematic-isotropic interface, the scaled anchoring coefficient $\mathrm{B}$ is of the order of magnitude of $0.01 .^{40}$ The anchoring strength $\mathrm{W}$ at the nematic-air interface is about several orders of magnitude larger than the anchoring strength at the nematic-isotropic interface. However, as the surface tension at the nematic-air interface is higher than the surface tension at the nematic-isotropic interface ${ }^{23 a, 41}$ the scaled anchoring coefficient $\mathrm{B}=\mathrm{W} / \gamma$ is taken to be in the range $-0.1<\mathrm{B}<-0.01$.

The plots of normal angle $\varphi(\mathrm{x})$ and the corresponding surface reliefs $\mathrm{h}(\mathrm{x})$ as a function of the distance " $\mathrm{x}$ ", for different $\mathrm{B}$ and $\mathrm{p}_{0}$ are shown in Fig. 2 and Fig.3, respectively. As expected, the periodicity of surface relief $\lambda$ equals the pitch, $\mathrm{p}_{0}$ and the amplitude are in the nanometer range, consistent with experimental findings. ${ }^{21 a}$, 42 Increasing both parameters $\mathrm{B}$ and $\mathrm{p}_{0}$ results in higher amplitudes. 


\subsection{Pressure-Curvature Relations}

As at the nematic-air interface, the anchoring strength $\left(\mathrm{W} \approx 10^{-5} \mathrm{~J} / \mathrm{m}^{2}\right)$ is three orders of magnitudes smaller than the surface tension $\left(\gamma \approx 10^{-2} \mathrm{~J} / \mathrm{m}^{2}\right),{ }^{30}$ it would seem that there is no driving forces to deform the CLC free interfaces and a flat interface would minimize the free surface energy. However, the director pressure curvature is shown here to be a driving force that wrinkles the surface under weak anchoring (i.e. small B) and typical values of chirality (i.e $\mathrm{p}_{0}$ in the $\mu \mathrm{m}$ range). All pressures are scaled with the isotropic tension $\gamma_{0}$ and have units of $\mu \mathrm{m}^{-1}$.

Due to the orientational order of CLC interface, the capillary pressure contains three contributions: surface area reduction, surface area rotation, and director curvature (eqn (4)). The essential feature of chiral capillarity is the interaction of anisotropy (director $\mathbf{n}$ of fibers), micron-range chirality $\left(\mathrm{p}_{0}\right)$, helix direction $(\mathbf{H})$ and free surface topography. When the cholesteric helix is parallel to a flat surface, frustration driven by the unavoidable (due to periodic $\mathbf{n}$ ) presence of high surface energy drives the surface uncoiling of the helix and the periodic tilting of the interface. This is another example of pattern formation by frustration, ubiquitous in mesophases. ${ }^{8,43}$

A unique feature of liquid crystal surfaces ${ }^{28}$ is the presence of Laplace pressure (area dilation), Herrings pressure (area rotation), and director orientation gradients pressure, as revealed succinctly by the surface gradient of the capillary vector $\xi$ (eqn(5)). Herring's pressure forms the basis of anisotropic crystal morphologies ${ }^{28}$ and is included here as $\mathrm{P}_{\text {rotation. }}$ As the Herring's pressure depends on curvature, it is only the orientation pressure $\mathrm{P}_{\text {director }}$ that wrinkles the surface with a wavelength that reflects the periodicity of the director field. Extracting the curvature in eqn(5) clearly shows that it is the ratio of a wrinkling driving force $\left(-\mathrm{P}_{\text {director }}\right.$ ) to a resistance to wrinkling (capillary tension coefficients):
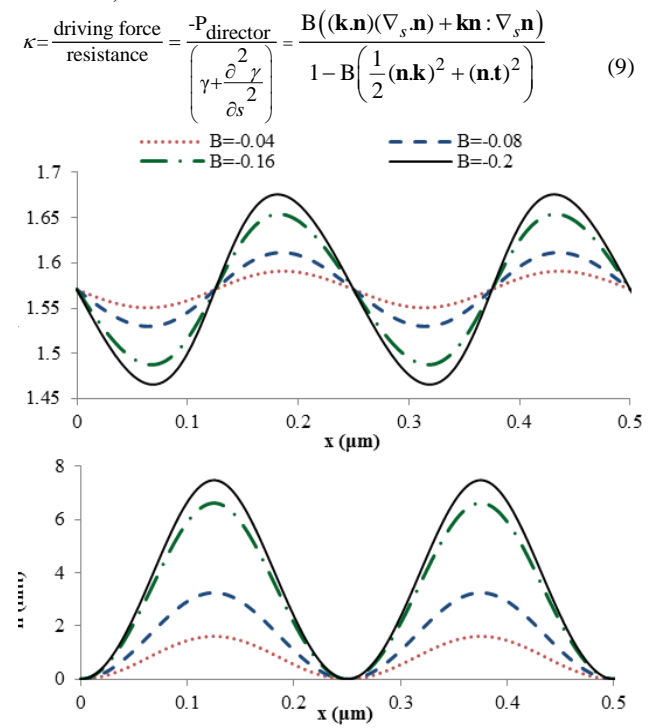

Figure.2 The numerical solutions $\varphi(x)$ and $h(x)$ for $\mathrm{p}_{0}=0.5 \mu \mathrm{m}$ and different values of $\mathrm{B}=-0.04,-0.08,-0.16$, and -0.2 where the capillary tension coefficients are the usual Laplace terms plus the Herring's coefficient ${ }^{28}$ given by the second derivative $\frac{\partial^{2} \gamma}{\partial \mathbf{k}^{2}}=$ $\mathbf{t t}:\left(\partial\left(\mathbf{t t} \cdot \frac{\partial \gamma}{\partial \mathbf{k}}\right) \partial \mathbf{k}\right)$; the last ratio is obtained by scaling with $\gamma_{0}$. Clearly as $P_{\text {director }}=0 \rightarrow \kappa=0$ (see also Appendix C). This is illustrated in Fig.4 through 3-D representation of surface curvature, $\kappa$, and associated pressure directors, $\mathrm{P}_{\text {director, }}$ and normal angle, $\varphi$, for two anchoring coefficients and three chirality values. Fig.4 shows that for all values of the anchoring coefficients and chiralities, the zero pressure director results in a flat surface (zero curvature). The horizontal diameter corresponds to the zero pressure director $\left(\mathrm{P}_{\text {director }}=0\right)$. Using scaling arguments, the $\mathrm{P}_{\text {director }}$ scales as:

$$
\mathrm{P}_{\text {director }}=\operatorname{order}\left(\frac{\mathrm{B}}{\mathrm{p}_{0}}\right)
$$

Therefore from eqns $(9,10)$ we see that the maximum curvature will increase with $\mathrm{B}$ and decrease with $\mathrm{p}_{0}$, in agreement with computations. This dependence is manifested in the 3-D plots of the surface curvature for different anchoring coefficients $(\mathrm{B}=-0.05$, and -0.1$)$ and chirality $\left(\mathrm{p}_{0}=0.5,1\right.$, and $\left.5 \mu \mathrm{m}\right)$, as shown in Fig.4(a) and Fig.4(b) respectively.

Fig.5 shows the three scaled surface pressures as a function of " $x$ " for two anchoring coefficients and $\mathrm{p}_{0}=0.5 \mu \mathrm{m}$. The ellipsoids correspond to the director orientation. Pressure extrema (and surface relief extrema as in Figs. $(2,3)$ ) occur at planar and homeotropic orientation. The Herring's pressure $\mathrm{P}_{\text {rotation }}$ is always positive and alternates its phase along each cycle, such that when the director angle is $\pi / 4<\theta<\pi / 2$ dilation and rotation are in-phase and when $0<\theta<\pi / 4$, rotation and director curvature are in-phase. Dilation and director curvature pressures are always out-of-phase. In addition its amplitude also oscillates. Increasing the anchoring strength increases the magnitude of all pressures.
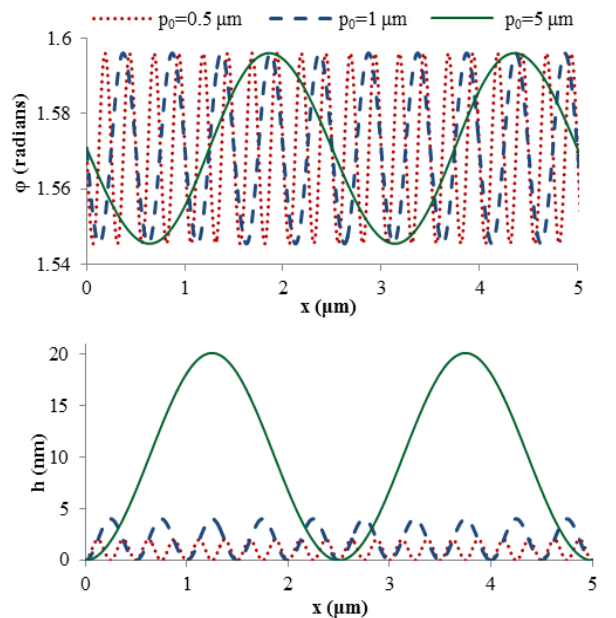

Figure. 3 The numerical solutions $\varphi(x)$ and $h(x)$ for $B=-0.05$ and different values of $\mathrm{p}_{0}=0.5,1$ and $5 \mu \mathrm{m}$ 

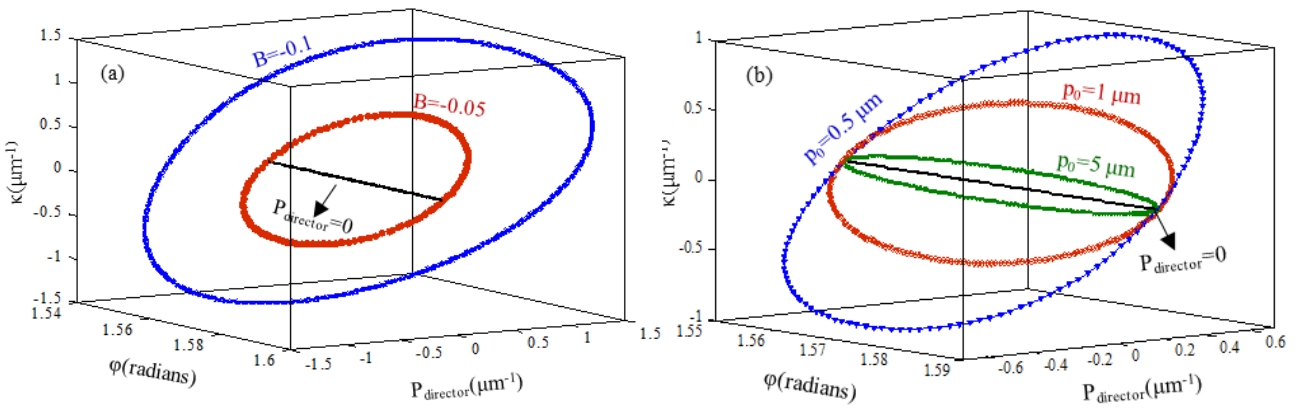

Figure.4 3-D representation of the surface curvature and associated pressure directors $P_{\text {director }}$ and normal angle $\varphi .\left(\right.$ a) $\mathrm{p}_{0}=0.5 \mu \mathrm{m}, \mathrm{B}=-0.05,-0.1$ and (b) $\mathrm{B}=-0.05, \mathrm{p}_{0}=0.5,1$, and $5 \mu \mathrm{m}$. The diameter corresponds to the zero pressure director $\left(\mathrm{P}_{\text {director }}=0\right)$.

The polar plots of the three scaled capillary pressures as a function of anchoring $B$ and chirality $\mathrm{p}_{0}$, are shown in Fig.6 and Fig.7 respectively. The angular coordinate is the director field $\theta$. The fourfold symmetry reflects the facts that the pressure extrema are at $0, n \pi / 2 ; n=\{ \pm 1,2, \ldots\}$ and that all pressures vanish at $n \pi / 4 ; n=\{ \pm$ $1,3 \ldots\}$. The figure shows that pressure asymmetry is strongest for the

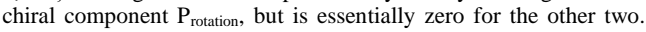
Fig.7 shows polar plots of pressure as a function of $\mathrm{p}_{0}$. Decreasing chirality decreases all pressures as the wave-length of the undulation increases. Changing $\mathrm{p}_{0}$ does not affect the degree of asymmetry between the lobes of these pressures.
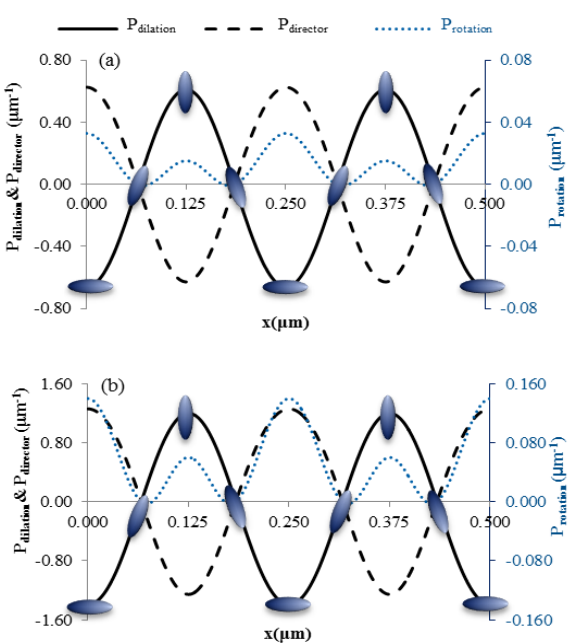

Figure 5. Pressure profiles for $\mathrm{P}_{\text {dilation }}, \mathrm{P}_{\text {rotation, }}$, and $\mathrm{P}_{\text {director }}$ as a function of distance " $\mathrm{x}$ ". (a) $\mathrm{B}=-0.05$ and $\mathrm{p}_{0}=0.5 \mu \mathrm{m}$ and (b) $\mathrm{B}=-0.1$ and $\mathrm{p}_{0}=0.5$ $\mu \mathrm{m}$. The ellipsoid corresponds to the director orientation.

\subsection{CLC Surface Energies}

The total surface energy is defined by $\mathrm{F}_{\mathrm{s}}=\int \gamma \cdot \mathrm{dA},{ }^{44}$ and for an initially flat surface of area $L^{2}$, the total scaled surface energy $\varepsilon_{\mathrm{T}} / \gamma_{0} \mathrm{~L}^{2}$ is:

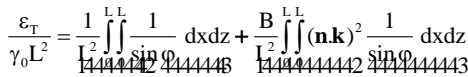

$$
\begin{aligned}
& \text { isotropic surface tension anchoring energy }
\end{aligned}
$$

Fig. 8 shows the variations of the total surface energy with the two surface energy contributions for various B in comparison with the flat surface energy contributions. Fig.8a shows the total scaled surface energy of the wrinkled and flat surfaces as a function of anchoring B. Increasing the magnitude of $B$ increases the energy difference between the flat and undulating surfaces. The figure demonstrates that the total energy monotonically decreases by increasing the magnitude of $B$. Fig. $8 \mathrm{~b}$ shows the different contributions of the profiles shown in Fig.8a. The undulation is driven by the anisotropic surface energy despite the increase in the isotropic energy. Also the decrease in anisotropic energy is significantly augmented by the undulations.

Fig.9 shows the corresponding energy contributions and behaviour as a function of chirality. The Figure shows that the isotropic surface tension energy and the anchoring energy for a particular value of anchoring $(\mathrm{B}=-0.05)$ are almost independent of chirality. Although the undulating surface has a higher isotropic energy compared to the flat, the lower anisotropic energy yields the undulating surface to a lower total surface energy compared to the flat surface reference line (Fig.9(a)).

\subsection{Undulation Scaling Law and Validation}

Using a standard order of magnitude analysis based on eqn (4), we find a revealing close form expression for the maximum amplitude $\mathrm{h}_{\max }$ as a function of $\mathrm{B}$ and $\mathrm{p}_{0}$ :

$$
\mathrm{h}_{\max }=\frac{\mathrm{Bp}_{0}}{1+\delta \mathrm{B}}
$$

The numerical results indicate that $\delta=10.71 B^{-1.02}$. The prediction is that the ratio of amplitude/periodicity is essentially a linear function of the scaled anchoring $B: \frac{h_{\max }}{p_{0}}=0.085 B$. Since the value of $B$ for the interface between the chiral nematic and the isotropic phase/air usually is in the range $-0.1<B<-0.01$, the estimated amplitude of surface undulation is about one percent of the undulation wavelength.
Formatted: Not Highlight 
The theoretical estimate, based on the shape equation, of the depth-to-period ratio is consistent with the nano-scale surface structures have been experimentally observed in a variety of polymeric and biological CLC. Periodic surface structure with amplitude of the order of hundred nanometers and a periodicity of the order of few micrometers spontaneously appeared from evaporating droplets of collagen solutions on glass substrates were detected by Maeda using an atomic force microscope (AFM). ${ }^{45}$ The periodic surface relief found in his work is very similar to the periodic undulations observed by Kirkwood and Fuller in a collagen film with twisted plywood architecture. ${ }^{11}$ Besides, the AFM images of sheared nano crystalline cellulose thin films showed two different scale periodical gratings: the primary periodic structure perpendicular to the shear direction and a smoother texture characterized by a secondary periodic structure which is very similar to the surface modulation found in Tulip "Queen of the Night" petals. ${ }^{20}$ The estimated values of the parameter B for several surface nano-undulations of CLC (refs.11, 20-21, 23a, 42, 45) are shown in Table.1. The results show that the predicted values of the parameter B using the scaling law are consistent with the anchoring energy coefficients for the CLC/air interface.

Table.1 Validation of the scaling law (eqn(10) with experimentally observed nano-scale surface undulations in CLCs and biological plywoods.

\begin{tabular}{lcccc}
\hline Experiments & $\begin{array}{c}\mathrm{h} \\
(\mathrm{nm})\end{array}$ & $\lambda(\mu \mathrm{m})$ & $\mathrm{B}^{\text {fitted }}$ \\
\hline
\end{tabular}

$\begin{array}{llll}\text { Chiral polymer }^{21 \mathrm{a}} & 2.5 & 0.63 & 0.028\end{array}$

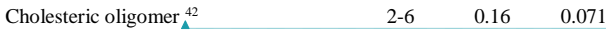

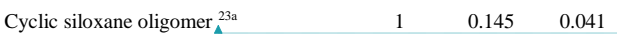

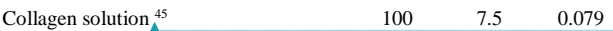

\begin{tabular}{lccc} 
Liquid erystalline collagen & 11 & 8 & 0.110 \\
Cellulosic cholesteric film & \multicolumn{4}{|c|}{} & 5 & 0.5 & 0.059 \\
\hline
\end{tabular}

\section{Conclusions}

This paper has used a non-linear nemato-capillarity shape equation to describe the main mechanisms driving nano-scale surface undulations in chiral nematic liquid crystals as shown in plant-based plywoods and various cholesteric liquid crystals. The generalized Laplace equation based on the Cahn-Hoffman capillarity vector formalism was formulated and used as an efficient tool to analyse surface reliefs in plant-based plywoods. The resulting chiral capillary equation admits stable spatially periodic solutions describing surface wrinkling, where the amplitude is in the order of few nms and the wave-length is in order of $\mu \mathrm{ms}$. The role of three capillary pressure contributions (surface area change, surface area rotation, and director curvature) have been elucidated and the influence of chirality and surface anchoring has been characterized. The director pressure has been identified as the fundamental driving force that generates the surface nano-scale undulations. The model predictions show that the director pressure vanishes for a planar surface with a uniform tangential helix vector and results in a flat surface. A scaling law for the chirality-driven surface wrinkling shows that the ratio of amplitude-to-period is a linear function of the ratio of anchoring strength to isotropic surface tension $\left(0.085 \times W / \gamma_{0}\right)$. The scaling law is validated with experimental values available in literature for surface undulations observed in CLCs and biological plywoods. Since the pitch $\mathrm{p}_{0}$ of cholesteric liquid crystals and plywoods is sensitive to temperature, water content, $\mathrm{pH}$, and external fields we expect new functional material surfaces that operate through the chiral capillarity mechanism described here. Further work is currently in progress to characterize water-based surface actuation mechanism through interaction of anisotropic interfacial tension and chirality changes through hydration.
Formatted: Not Highlight

\section{Field Code Changed}

Field Code Changed

Formatted: Not Highlight

Formatted: Not Highlight
Field Code Changed

Field Code Changed

Field Code Changed

Field Code Changed

Field Code Changed

\section{Field Code Changed}

Field Code Changed

Field Code Changed

Formatted: Not Highlight

Field Code Changed

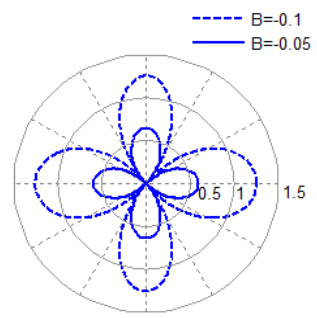

(a)

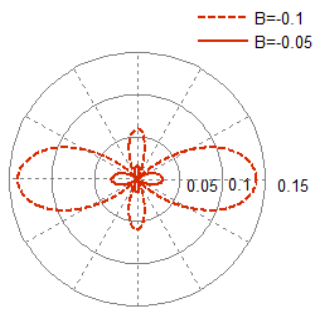

(b)

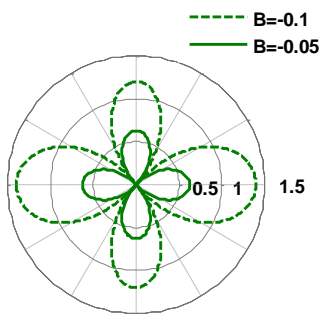

(c)

Figure.6 Polar plots of the three scaled capillary pressures a) $P_{\text {dilation }}\left(\mu \mathrm{m}^{-1}\right)$ b) $P_{\text {rotation }}\left(\mu \mathrm{m}^{-1}\right)$ c) $\mathrm{P}_{\text {director }}\left(\mu \mathrm{m}^{-1}\right)$ for $\mathrm{B}=-0.05$ and -0.1 , and $\mathrm{p}_{0}=0.5 \mu \mathrm{m}$. 


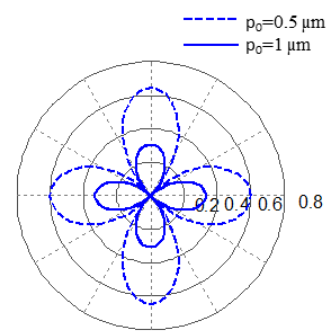

(a)

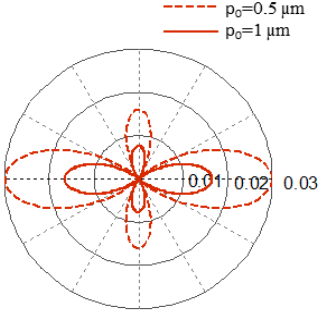

(b)

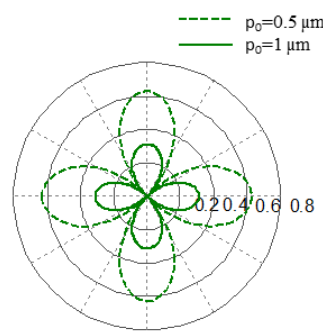

(c)

Figure.7 Polar plots of the three scaled capillary pressures a) $P_{\text {dilation }}\left(\mu \mathrm{m}^{-1}\right)$ b) $P_{\text {rotation }}\left(\mu \mathrm{m}^{-1}\right)$ c) $P_{\text {director }}\left(\mu \mathrm{m}^{-1}\right)$ for $\mathrm{p}_{0}=0.5 \& 1 \mu \mathrm{m}$ and $\mathrm{B}=-0.5$

\section{Appendix A}

Cahn-Hoffman capillarity vector thermodynamics for CLC interfaces

The purpose of this Appendix is to derive the Cahn-Hoffman capillarity vector formulations for CLC interfaces. The nematic capillarity vector is defined by the gradient of the scalar field $\mathrm{r} \gamma::^{35}$

$\xi(\mathbf{n}, \mathbf{k})=\nabla[\mathrm{r} \gamma(\mathbf{k})]$

Where $r$ is the magnitude of surface position vecto

Noting thatd $(\mathrm{r} \gamma)=\nabla(\mathrm{r} \gamma)$. dr $\mathbf{r}$, the gradient of $\mathrm{r} \gamma$ yield:

$\xi(\mathbf{n}, \mathbf{k})=\nabla[\mathrm{r} \gamma(\mathbf{k})]=\gamma \frac{\partial \mathrm{r}}{\partial \mathbf{r}}+\mathrm{r} \frac{\mathrm{d} \gamma}{\mathrm{d} \mathbf{r}}=\gamma \mathbf{k}+\mathbf{I}_{\mathrm{s}} \cdot \frac{\mathrm{d} \gamma}{\mathrm{d} \mathbf{k}}$

(A2) $\frac{\partial \boldsymbol{\xi}_{\perp}}{\partial \boldsymbol{k}}: \nabla_{\mathrm{s}} \boldsymbol{k}=\gamma \boldsymbol{I}_{\mathrm{s}}: \nabla_{\mathrm{s}} \boldsymbol{k}$

Thus the normal and tangential components of capilarity vector According to eqn(A6), the area rotation contribution becomes: for CLC interfaces are:

$$
\begin{aligned}
& \xi_{\perp}(\mathbf{n}, \mathbf{k})=\gamma \mathbf{k} \\
& \xi_{\square}(\mathbf{n}, \mathbf{k})=\mathbf{I}_{\mathrm{s}} \cdot \frac{\mathrm{d} \gamma}{\mathrm{d} \mathbf{k}}=\left(\mathbf{I}_{\mathrm{s}} \cdot \mathbf{n}\right) \frac{\mathrm{d} \gamma}{\mathrm{d}(\mathbf{n} \cdot \mathbf{k})}=\gamma^{\prime} \mathbf{n}
\end{aligned}
$$

$$
\begin{aligned}
\frac{\partial \boldsymbol{\xi}_{\|}}{\partial \boldsymbol{k}}: \nabla_{\mathrm{s}} \cdot \boldsymbol{k} & =\mathrm{W}\left(\boldsymbol{n n}-(\boldsymbol{n} \cdot \boldsymbol{k})^{2} \boldsymbol{I}\right): \nabla_{\mathrm{s}} \cdot \boldsymbol{k} \\
& =\left(\mathrm{W}(\boldsymbol{n} \cdot \boldsymbol{t})^{2}-\frac{\mathrm{W}}{2}(\boldsymbol{n} \cdot \boldsymbol{k})^{2}\right) \kappa
\end{aligned}
$$

Where $\gamma^{\prime}=\frac{d \gamma}{d(\boldsymbol{n} \cdot \boldsymbol{k})}$ and $\mathrm{n}_{\|}=\mathrm{I}_{\mathrm{s}} \cdot \mathbf{n}$ is the tangential component of the surface director field. Noticing that $\mathbf{I}_{\mathrm{s}}$ is the $2 \times 2$ unit surface dyadic: $\mathbf{I}_{\mathbf{s}}=\mathbf{I}-\mathbf{k k}$ where $\mathbf{I}$ is the $3 \times 3$ volumetric unit tensor, we have:

The director curvature contribution is found using eqn(A6), to obtain:

$\frac{\partial \boldsymbol{\xi}_{\|}}{\partial \boldsymbol{n}}=\frac{\partial}{\partial \boldsymbol{n}}(\mathrm{W}(\mathbf{n} . \mathbf{k})(\boldsymbol{n}-(\mathbf{n . k}) \mathbf{k}))$

$=\mathrm{W} \mathbf{k n}-2 \mathrm{~W}(\boldsymbol{k} \cdot \boldsymbol{n}) \mathbf{k k}+\mathrm{W}(\mathbf{n} \cdot \mathbf{k}) \mathrm{I}$

(A10 a)

$\xi_{\|}(\mathbf{n}, \mathbf{k})=\mathbf{I}_{\mathrm{s}} \cdot \frac{\mathrm{d} \gamma}{\mathrm{dk}}=(\mathbf{I}-\mathbf{k k}) \cdot \frac{\mathrm{d} \gamma}{\mathrm{d} \mathbf{k}}=\mathbf{I} \cdot \frac{\mathrm{d} \gamma}{\mathrm{d} \mathbf{k}}-\mathbf{k k} \cdot \frac{\mathrm{d} \gamma}{\mathrm{d} \mathbf{k}}$

Using the Rapini-Papoular surface free energy $\gamma=\gamma_{0}+\frac{\partial \boldsymbol{\xi}_{\|}}{\partial \boldsymbol{n}}: \nabla_{\mathrm{s}} \boldsymbol{n}=\frac{\partial \boldsymbol{\xi}_{\|}}{\partial \boldsymbol{n}}: \frac{\partial \mathbf{n}}{\partial \mathrm{s}}$

$\frac{\mathrm{w}}{2}(\mathbf{n} \cdot \mathbf{k})^{2}{ }^{29}$ we get:

$$
\frac{\mathrm{d} \gamma}{\mathrm{d} \mathbf{k}}=\mathrm{W}(\mathbf{n} \cdot \mathbf{k}) \mathbf{n}
$$

Substituting eqn (A5), we obtain the tangential component of the capillarity vector:

$\xi_{\|}(\mathbf{n}, \mathbf{k})=\mathrm{W}(\mathbf{n} . \mathbf{k}) \mathbf{n}-\mathrm{W}(\mathbf{n . k})^{2} \mathbf{k}=\mathrm{W}(\mathbf{n} . \mathbf{k})(\mathbf{n}-(\mathbf{n . k}) \mathbf{k})$

\section{Field Code Changed}

Field Code Changed

\section{Field Code Changed}

Field Code Changed

Field Code Changed

Field Code Changed

Field Code Changed

Field Code Changed

Field Code Changed

\section{Field Code Changed}

Field Code Changed

Field Code Changed

Field Code Changed

Field Code Changed

Field Code Changed 

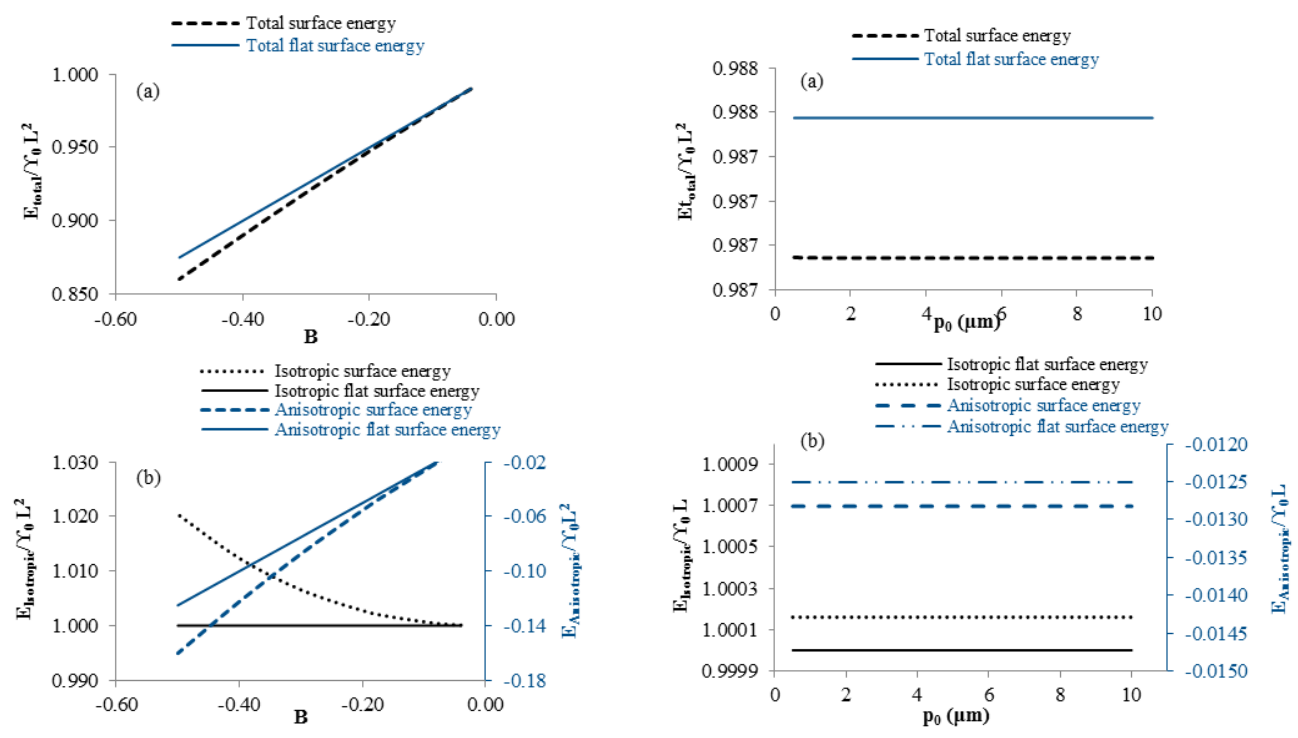

\section{Appendix B}

Director curvature pressure

The purpose of this Appendix is : (i) to derive a general expression of the director curvature pressure $\mathrm{p}_{\mathrm{N}}$, (ii) to determine generic sufficient condtions under which $\mathrm{p}_{\mathrm{N}}=0$, and (iii) to use (i) and (ii) to show that for a planar surface with a uniform tangential helix vector then $\mathrm{p}_{\mathrm{N}}=0$ and no surface wrinkling can be observed as predcited by ref.23a using other approaches.

(i) General expression for the director curvature pressure $\left(p_{N}\right)$. Using eqn(4), the director curvature contribution to the capillary pressure, $\mathrm{p}_{\mathrm{N}}$ appears due to orientation gradients:

$$
\begin{aligned}
& \mathrm{p}_{\mathrm{N}}=\frac{\partial \boldsymbol{\xi}_{\|}}{\partial \boldsymbol{n}}: \nabla_{\mathrm{s}} \cdot \boldsymbol{n} \\
& \mathrm{p}_{\mathrm{N}}=\mathrm{W}\left((\boldsymbol{k} \cdot \boldsymbol{n})\left(\nabla_{\mathrm{s}} \cdot \boldsymbol{n}\right)+\boldsymbol{k} \boldsymbol{n}: \nabla_{\mathrm{s}} \boldsymbol{n}\right)
\end{aligned}
$$

To analyse this expression further we need the covariant surface gradient of the director field $\nabla_{s} \mathbf{n}$ (for details see ref.46):

$$
\begin{aligned}
\nabla_{\mathrm{s}} \mathbf{n}=\mathbf{a}^{\alpha} \mathbf{n}_{, \alpha} & =\left(\mathrm{n}_{\beta ; \alpha}-\mathrm{b}_{\beta \alpha} \mathrm{n}_{\perp}\right) \mathbf{a}^{\alpha} \mathbf{a}^{\beta}+\left(\mathrm{n}_{\perp, \alpha}+\mathrm{b}_{\beta \alpha} \mathrm{n}^{\beta}\right) \mathbf{a}^{\alpha} \mathbf{k} \\
& =\left(\mathrm{n}_{\beta ; \alpha} \mathbf{a}^{\alpha} \mathbf{a}^{\beta}-\mathrm{n}_{\perp} \mathbf{b}\right)+\left(\nabla_{\mathrm{s}} \mathrm{n}_{\perp}+\mathbf{b} \cdot \mathbf{n}\right) \mathbf{k}
\end{aligned}
$$

where a semicolon denotes covariant differentiation, $\mathbf{a}_{\alpha}$ are the two tangential base vectors, $\mathbf{a}^{\alpha}$ are the two reciprocal base vectors, the director field is $\mathbf{n}=\mathrm{n}_{\beta} \mathbf{a}^{\beta}+\mathrm{n}_{\perp} \mathbf{k}$, and the curvature tensor $\mathbf{b}$ is:

$$
\mathbf{b}=-\frac{\partial \mathbf{k}}{\partial \mathbf{R}}=-\nabla_{\mathrm{S}} \mathbf{k}, \nabla_{\mathrm{S}}(*)=\mathbf{I}_{\mathrm{S}} \cdot \nabla_{\mathrm{S}}(*)=\frac{\partial(*)}{\partial \mathbf{R}}=\mathbf{a}^{\alpha} \frac{\partial(*)}{\partial \mathrm{u}^{\alpha}}
$$

where $\mathbf{R}$ is the position vector given parametrically by $\mathbf{R}=$ $\mathbf{R}\left(u^{\alpha}\right), \alpha=1,2$ and $u^{\alpha}$ are the surface coordinates. The average curvature $\mathrm{H}$ and the Gaussian or total curvature $\kappa$ are:

$$
\begin{array}{r}
2 \mathrm{H}=\mathbf{I}_{\mathrm{s}}: \mathbf{b}=-\nabla_{\mathrm{s}} \cdot \mathbf{k}=-\mathbf{a}^{\alpha} \frac{\partial \mathbf{k}}{\partial \mathrm{u}^{\alpha}}=\mathrm{b}_{\alpha}^{\alpha}=\left(\mathrm{c}_{1}+\mathrm{c}_{2}\right) \\
\mathrm{K}=-\frac{1}{2} \varepsilon_{\mathrm{s}}:\left(\mathbf{b} \cdot \varepsilon_{\mathrm{s}} \cdot \mathbf{b}\right)=\frac{1}{2} \varepsilon^{\alpha \beta} \varepsilon^{\gamma \delta} \mathrm{b}_{\alpha \gamma} \mathrm{b}_{\beta \delta}=\left(\mathrm{c}_{1} \mathrm{c}_{2}\right)
\end{array}
$$

where $c_{1}$ and $c_{2}$ are the radius of curvature and $\boldsymbol{\varepsilon}_{s}$ is the dyadic surface

The surface director gradient $\nabla_{s} \mathbf{n}$ can then be decomposed into the $2 \times 2$ symmetric surface gradient tensor $\mathbf{A}$, the $2 \times 2$ antisymmetric

$\nabla_{\mathrm{s}} \mathbf{n}=\mathbf{A}+\mathbf{W}+\mathbf{R}$ unit alternator:

$$
\varepsilon_{\mathrm{s}}=-\mathbf{k} \times \mathbf{I}_{\mathrm{s}}=-\mathbf{I}_{\mathrm{s}} \times \mathbf{k}=-\mathbf{k} \times \mathbf{I}=-\mathbf{I} \times \mathbf{k}
$$

$$
=\mathbf{a}^{\alpha} \mathbf{a}^{\beta} \varepsilon_{\alpha \beta}=\mathbf{a}_{\alpha} \mathbf{a}_{\beta} \varepsilon^{\alpha \beta}
$$
surface gradient tensor $\mathbf{W}$, and the $2 \times 1$ surface gradient tensor $\mathbf{R}$. (B7a)

$$
\mathbf{A}=\mathrm{A}_{\alpha \beta} \mathbf{a}^{\alpha} \mathbf{a}^{\beta}
$$$$
\mathrm{A}_{\alpha \beta}=\mathrm{A}_{\beta \alpha}=\mathrm{n}_{(\beta ; \alpha)}-\mathrm{n}_{\perp} \mathrm{b}_{\alpha \beta} ; \mathrm{n}_{(\beta ; \alpha)}=\frac{1}{2}\left(\mathrm{n}_{\beta ; \alpha}+\mathrm{n}_{\alpha ; \beta}\right)
$$

Field Code Changed

\section{Field Code Changed}

Field Code Changed

Field Code Changed

Field Code Changed Field Code Changed Field Code Changed

Field Code Changed Field Code Changed Field Code Changed Field Code Changed Field Code Changed

$\mathbf{W}=\mathrm{W}_{\alpha \beta} \mathbf{a}^{\alpha} \mathbf{a}^{\beta} ;$

$\mathrm{W}_{\alpha \beta}=-\mathrm{W}_{\beta \alpha}=\mathrm{n}_{[\beta ; \alpha]} ; \mathrm{n}_{[\beta ; \alpha]}=\frac{1}{2}\left(\mathrm{n}_{\beta ; \alpha}-\mathrm{n}_{\alpha ; \beta}\right)$ (B7c)

Field Code Changed

Field Code Changed

Field Code Changed 


$$
\mathbf{R}=\mathrm{R}_{\alpha \mathrm{n}} \mathbf{a}^{\alpha} \mathbf{k} ; \mathrm{R}_{\alpha \mathrm{n}}=\mathrm{n}_{\perp, \alpha}+\mathrm{b}_{\alpha \beta} \mathrm{n}^{\beta}
$$
(B7d)

In addition, the surface divergence of the director is found from eqn(B2) to be:

$$
\begin{aligned}
\nabla_{\mathrm{s}} \mathbf{n} & =\mathbf{a}^{\alpha} \mathbf{n}_{, \alpha}=\left(\mathrm{n}_{\beta ; \alpha}-\mathrm{b}_{\beta \alpha} \mathrm{n}_{\perp}\right) \mathbf{a}^{\alpha} \mathbf{a}^{\beta} \\
& =\mathbf{I}_{\mathrm{s}}: \mathbf{A}=\mathrm{n}_{\alpha ; \alpha}-2 H \mathrm{n}_{\perp}
\end{aligned}
$$

Replacing eqns(B7a-B8) into eqn(B1b) we find a general and detailed expression for the director pressure in terms of director component $\left(n_{\alpha}, n_{\alpha: \alpha}, n_{\perp}, n_{\|}\right)$and curvatures $\left(H, b_{\alpha, \beta}\right)$ :

$$
\begin{aligned}
\mathrm{p}_{\mathrm{N}} & =\mathrm{W}\left((\mathbf{n} \cdot \mathbf{k}) \mathbf{I}_{\mathrm{s}}: \mathbf{A}+\mathbf{n} \cdot \mathbf{R} \cdot \mathbf{k}\right) \\
& =\mathrm{W}\left(\left(\mathrm{n}_{(\alpha ; \alpha)}-2 \mathrm{n}_{\perp} \mathrm{H}\right) \mathrm{n}_{\perp}+\left(\mathrm{n}_{\perp, \alpha}+\mathrm{b}_{\alpha \beta} \mathrm{n}^{\beta}\right) \mathrm{n}_{\alpha}\right)
\end{aligned}
$$

(ii) Vanishing director curvature pressure $\left(p_{N}=0\right)$.

Here we analyse some likely cases of $\mathrm{p}_{\mathrm{N}}=0$ for: (a) $2 \mathrm{D}$ surfaces and then (b) 1D planar lines.

(a) For flat surfaces, eqn(B9) it simplifies to:

$$
\mathrm{p}_{\mathrm{N}}(\mathbf{b}=\mathbf{0})=\mathrm{W}\left(\mathrm{n}_{(\alpha ; \alpha)} \mathrm{n}_{\perp}+\mathbf{n} \cdot \mathbf{a}^{\alpha} \mathrm{n}_{\perp, \alpha}\right)
$$

If the director field is homeotropic, $\mathrm{n}_{(\alpha ; \alpha)}=\mathbf{n} \cdot \mathbf{a}^{\alpha}=0$ and $\mathrm{p}_{\mathrm{N}}=0$. If the director is tangential $\mathrm{n}_{\perp, \alpha}=\mathrm{n}_{\perp}=0$ and $\mathrm{p}_{\mathrm{N}}=0$.

(b) For 1D planar lines, the director pressure is:

$$
\mathrm{P}_{\mathrm{N}}=\mathrm{W}(\mathbf{t} \cdot \mathbf{n})\left(\mathbf{k} \cdot \frac{\partial \boldsymbol{n}}{\partial \mathrm{s}}\right)+\mathrm{W}(\boldsymbol{n} \cdot \boldsymbol{k})\left(\mathbf{t} \cdot \frac{\partial \boldsymbol{n}}{\partial \mathrm{s}}\right)
$$

where $\mathbf{t}$ is the unit tangent, $\mathbf{k}$ the unit normal and s the arc-length. For homeotropic and planar straight lines we find $\mathrm{p}_{\mathrm{N}}=0$. For straight lines with line gradients, using rectangular $(\mathrm{x}, \mathrm{y}, \mathrm{z})$ coordinates with unit vectors $\left(\boldsymbol{\delta}_{\mathrm{x}}=\mathrm{t}, \boldsymbol{\delta}_{\mathrm{y}}=\mathbf{k}, \boldsymbol{\delta}_{\mathrm{z}}\right)$ and a director filed $\mathbf{n}=\mathrm{n}_{\mathrm{x}} \boldsymbol{\delta}_{\mathrm{x}}+\mathrm{n}_{\mathrm{y}} \boldsymbol{\delta}_{\mathrm{y}}+$ $\mathrm{n}_{\mathrm{z}} \boldsymbol{\delta}_{\mathrm{z}}$, the pressure equation (eqn (B11)) becomes:

$$
\mathrm{p}_{\mathrm{N}}=\mathrm{W}\left(\mathrm{n}_{\mathrm{y}} \mathrm{n}_{\mathrm{x}, \mathrm{x}}+\mathrm{n}_{\mathrm{x}} \mathrm{n}_{\mathrm{y}, \mathrm{x}}\right)
$$

which vanishes when $\mathrm{n}_{\mathrm{x}} \mathrm{n}_{\mathrm{y}}=\mathbf{C}=$ constant. Hence under planar or homeotropic orientation there is no director pressure. Using the unit length of the director $\mathbf{n . n}=1$, no director pressure is generated for director field satisfying:

$$
\mathrm{n}_{\mathrm{y}}^{4}+\mathrm{n}_{\mathrm{z}}^{2} \mathrm{n}_{\mathrm{y}}^{2}-\mathrm{n}_{\mathrm{y}}^{2}+\mathrm{c}^{2}=0
$$

(iii) Proof of zero director curvature pressure for planar surfaces $(H=0)$ with tangential cholesteric helix $(\boldsymbol{h}=\boldsymbol{t})$.

When the cholesteric helix is tangential to the straight line then $\mathbf{s}=\mathrm{x}, \mathbf{t}=\boldsymbol{\delta}_{\mathbf{x}}=$ constant, $\boldsymbol{\delta}_{\mathbf{x}} \cdot \mathbf{n}=0, \boldsymbol{\delta}_{\mathrm{x}} \cdot\left(\frac{d n}{d x}\right)=0$.

Using eqn(B10) we find:

$$
\mathrm{p}_{\mathrm{N}}=\mathrm{W}\{\left(\gamma_{\mathrm{y}} \cdot \mathbf{n}\right) \underbrace{\left(\delta_{\mathrm{x}} \cdot \frac{\mathrm{d} \mathbf{n}}{\mathrm{dx}}\right)}_{=0}+\underbrace{\left(\delta_{\mathrm{x}} \cdot \mathbf{n}\right)}_{=0}\left(\delta_{\mathrm{y}} \cdot \frac{\mathrm{d} \mathbf{n}}{\mathrm{dx}}\right)\}=0
$$

No director pressure is generated because the director gradients and the director components have no projection on the $\mathrm{x}$-axis.

\section{Appendix C}

Derivation of shape and normal angle equations
The purpose of this Appendix is to formulate the capillay shape equation for the splay-bend director.

The geometry of the free interface is characterized by a cylindrical surface such that its curvature in the z-direction is zero and focus on the projection $\mathbf{x}(\mathrm{s})$ in the $\mathrm{x}-\mathrm{y}$ plane (Fig.C1). The unit tangent $\mathbf{t}$ and the unit normal $\mathrm{N}$ to the surface are given by:

$$
\mathbf{t}(\mathrm{s})=\frac{\partial \mathbf{x}(\mathrm{s})}{\partial \mathrm{s}} \quad ; \quad \frac{\partial \mathrm{t}(\mathrm{s})}{\partial \mathrm{s}} \equiv \frac{\partial^{2} \mathbf{x}(\mathrm{s})}{\partial \mathrm{s}^{2}}=\mathbf{\kappa} \mathbf{k}(\mathrm{s})
$$

Where $\boldsymbol{\kappa}$ is the curvature, quantifying the deviation from linearity.

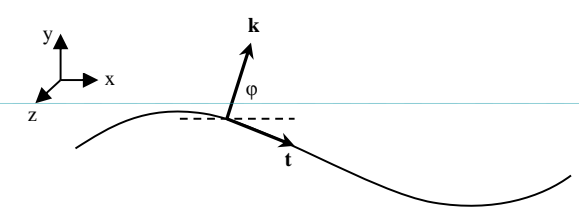

Figure.C1 Geometry of the free surface, unit normal $\mathbf{k}$, normal angle, unit tangent $\mathbf{t}$, and $(\mathrm{x}, \mathrm{y}, \mathrm{z})$ coordinate system.

Since $\mathbf{t}$ is a unit vector it can be expressed with the normal angle: $\boldsymbol{t}(\boldsymbol{x})=(\sin \varphi(\mathrm{x}),-\cos \varphi(\mathrm{x}), 0)$. In the normal angle parameterization the curvature is: $\boldsymbol{\kappa}=\frac{\mathrm{d} \varphi}{\mathrm{ds}}$. Using the definition: $\frac{d x}{d s}=\sin \varphi$, the director curvature pressure is $\frac{d n}{d s}=$ $\frac{\mathrm{dn}}{\mathrm{dx}} \frac{\mathrm{dx}}{\mathrm{ds}}=\frac{\mathrm{dn}}{\mathrm{dx}} \sin \varphi$, and $\kappa=\frac{\mathrm{d} \varphi}{\mathrm{dx}} \sin \varphi$. By substituting $\kappa$ and $\frac{d n}{d s}$ in eqn (5), the shape equation becomes:

$$
\begin{aligned}
p_{c} & =\left\{\left(1-\frac{B}{2}(\mathbf{n} \cdot \mathbf{k})^{2}+B(\mathbf{n} \cdot \mathbf{t})^{2}\right) \sin \phi\right\} \frac{d \phi}{d x} \\
& -\left\{B(\mathbf{k} \cdot \mathbf{n})\left(\frac{d \mathbf{n}}{d x} \cdot \mathbf{t}\right)+B(\mathbf{n} \cdot \mathbf{t})\left(\frac{d \mathbf{n}}{d x} \cdot \mathbf{k}\right)\right\} \sin \phi
\end{aligned}
$$

Setting $p_{c}=0$ and using the splay-bend director distribution $\mathbf{n}(x)$ : $\mathbf{n}(\mathrm{x})=(\cos \mathrm{qx}, \sin \mathrm{qx}, 0)$ and surface unit normal $\mathbf{k}(\mathrm{x})$ : $\mathbf{k}(\mathrm{x})=(\cos \varphi(\mathrm{x}), \sin \varphi(\mathrm{x}), 0)$, gives the governing nonlinear first order ODE for the normal angle $\varphi(x, B, q)$ :

$$
\frac{d \varphi}{d x}=\frac{q B \sin (\varphi)\left\{\sin ^{2}(\varphi-q x)-\cos ^{2}(\varphi-q x)\right\}}{\sin (\varphi)\left\{1-\frac{B}{2} \cos ^{2}(\varphi-q x)+B \sin ^{2}(\varphi-q x)\right.}
$$

\section{Acknowledgements}

Financial support for this research was provided by Le Fonds Quebecois de la Recherche sur la Nature et les Technologies (FQRNT). P. Rofouie is the recipient of post graduate scholarships from McGill Engineering Doctoral Awards (MEDA). The authors gratefully acknowledge Professor E. Doedel for guidance with the use of software package AUTO.

\section{References}

1. Gennes, P.-G. d.; Prost, J., The physics of liquid crystals. 2nd ed.; Clarendon Press; Oxford University Press: Oxford. New York, 1995; p xvi, 597 p.

\section{Field Code Changed}

Field Code Changed

Field Code Changed

Field Code Changed

Field Code Changed

Field Code Changed

Field Code Changed

\section{Field Code Changed}

Field Code Changed

Field Code Changed

Field Code Changed 
2. Neville, A. C., Biology of fibrous composites : development beyond the cell membrane. Cambridge University Press: New York, NY, USA, 1993; p vii, 214 p

3. Rey, A. D.; Herrera-Valencia, E. E.; Murugesan, Y. K., Structure and dynamics of biological liquid crystals. Liq Cryst 2014, 41 (3), 430-451.

4. (a) Bouligand.Y, Twisted Fibrous Arrangements in BiologicalMaterials and Cholesteric Mesophases. Tissue Cell 1972, 4 (2), 189-217; (b) De Luca, G.; Rey, A. D., Chiral front propagation in liquid-crystalline materials: Formation of the planar monodomain twisted plywood architecture of biological fibrous composites. Phys Rev E 2004, 69 (1); (c) De Luca, G.; Rey, A. D., Monodomain and polydomain helicoids in chiral liquid-crystalline phases and their biological analogues. Eur Phys $J E$ 2003, 12 (2), 291-302; (d) Rey, A. D.; Herrera-Valencia, E. E., Liquid crystal models of biological materials and silk spinning. Biopolymers 2012, 97 (6), 374-396.

5. Livolant, F.; Leforestier, A., Condensed phases of DNA: Structures and phase transitions. Prog Polym Sci 1996, 21 (6), 1115-1164. 6. Belamie, E.; Mosser, G.; Gobeaux, F.; Giraud-Guille, M. M., Possible transient liquid crystal phase during the laying out of connective tissues: alpha-chitin and collagen as models. J Phys-Condens Mat 2006, 18 (13), 115-129.

7. Giraudguille, M. M., Twisted Plywood Architecture of Collagen Fibrils in Human Compact-Bone Osteons. Calcified Tissue Int 1988, 42 (3), 167-180

8. Rey, A. D., Liquid crystal models of biological materials and processes. Soft Matter 2010, 6 (15), 3402-3429.

9. Smalyukh, I. I.; Zribi, O. V.; Butler, J. C.; Lavrentovich, O. D.; Wong, G. C. L., Structure and dynamics of liquid crystalline pattern formation in drying droplets of DNA. Phys Rev Lett 2006, 96 (17).

10. Miller, A. F.; Donald, A. M., Imaging of anisotropic cellulose suspensions using environmental scanning electron microscopy. Biomacromolecules 2003, 4 (3), 510-517.

11. Kirkwood, J. E.; Fuller, G. G., Liquid Crystalline Collagen: A SelfAssembled Morphology for the Orientation of Mammalian Cells. Langmuir 2009, 25 (5), 3200-3206.

12. Willcox, P. J.; Gido, S. P.; Muller, W.; Kaplan, D. L., Evidence of a cholesteric liquid crystalline phase in natural silk spinning processes. Macromolecules 1996, 29 (15), 5106-5110.

13. Sharma, V.; Crne, M.; Park, J. O.; Srinivasarao, M., Structural Origin 13. Sharma, V.; Crne, M.; Park, J. O.; Srinivasarao, M., Structural Origin
of Circularly Polarized Iridescence in Jeweled Beetles. Science 2009, of Circularly Polarized

325 (5939), 449-451.
14. Tan, T. L.; Wong, D.; Lee, P., Iridescence of a shell of mollusk Haliotis Glabra. Opt Express 2004, 12 (20), 4847-4854.

15. Vignolini, S.; Moyroud, E.; Glover, B. J.; Steiner, U., Analysing photonic structures in plants. $J R$ Soc Interface 2013, 10 (87).

16. Agez, G.; Bitar, R.; Mitov, M., Color selectivity lent to a cholesteric liquid crystal by monitoring interface-induced deformations. Soft Matter 2011, 7 (6), 2841-2847.

17. Whitney, H. M.; Kolle, M.; Andrew, P.; Chittka, L.; Steiner, U.; Glover, B. J., Floral Iridescence, Produced by Diffractive Optics, Acts As a Cue for Animal Pollinators. Science 2009, 323 (5910), 130-133.

18. Werbowyj, R. S.; Gray, D. G., Liquid-Crystalline Structure in Aqueous Hydroxypropyl Cellulose Solutions. Mol Cryst Liq Cryst 1976, 34 (4), 97-103.

19. (a) Yoneyama, H.; Kawabata, K.; Tsujimoto, A.; Goto, H., Preparation of iridescent-reflective poly(furan-co-phenylene)s by electrochemical polymerization in a cholesteric liquid crystal medium. Electrochem Commun 2008, 10 (7), 965-969; (b) Arrighi, V.; Cowie, J. M. G.; Vaqueiro, P.; Prior, K. A., Fine structure and optical properties of cholesteric films prepared from cellulose 4-methylphenyl urethane/Nvinyl pyrolinone solutions. Macromolecules 2002, 35 (19), 73547360; (c) Zhang, Y. P.; Chodavacrom, V. P.; Kirk P., Structured color humidity indicator from reversible pitch tuning in self-assembled nanocrystalline cellulose films. Sensor Actuat B-Chem 2013, 176, 692-697.

20. Fernandes, S. N.; Geng, Y.; Vignolini, S.; Glover, B. J.; Trindade, A. C.; Canejo, J. P.; Almeida, P. L.; Brogueira, P.; Godinho, M. H. Structural Color and Iridescence in Transparent Sheared Cellulosic Films. Macromol Chem Phys 2013, 214 (1), 25-32.

21. (a) Terris, B. D.; Twieg, R. J.; Nguyen, C.; Sigaud, G.; Nguyen, H. T., Force Microscopy of Chiral Liquid-Crystal Surfaces. Europhys Lett 1992, 19 (2), 85-90; (b) Cladis, P. E.; Kleman, M., Cholesteric Domain Texture. Mol Cryst Liq Cryst 1972, 16 (1-2), 1-\&; (c) Harth, K.; Schulz,
B.; Bahr, C.; Stannarius, R., Atomic force microscopy of menisci of freestanding smectic films. Soft Matter 2011, 7 (15), 7103-7111; (d) Zhang, C.; Edo, S.; Ishige, R.; Tokita, M.; Watanabe, J., Regular undulation morphology observed on fracture and film surfaces of chiral S-C* polymer. Macromolecules 2008, 41 (14), 5361-5364.

22. Rey, A. D., Capillary models for liquid crystal fibers, membranes, films, and drops. Soft Matter 2007, 3 (11), 1349-1368.

23. (a) Meister, R.; Dumoulin, H.; Halle, M. A.; Pieranski, P., Anchoring of a cholesteric liquid crystal at the free surface. J Phys Ii 1996, 6 (6), 827-844; (b) Meister, R.; Halle, M. A.; Dumoulin, H.; Pieranski, P., Structure of the cholesteric focal conic domains at the free surface. Phys Rev E 1996, 54 (4), 3771-3782.

24. Roland, J. C.; Reis, D.; Vian, B., Liquid-Crystal Order and Turbulence in the Planar Twist of the Growing Plant-Cell Walls. Tissue Cell 1992, 24 (3), 335-345.

25. Brett, C. T.; Waldron, K., Physiology and biochemistry of plant cell walls. 2nd ed.; Chapman \& Hall: London, 1996; p xiii, 255 p.

26. (a) Murugesan, Y. K.; Rey, A. D., Modeling Textural Processes during Self-Assembly of Plant-Based Chiral-Nematic Liquid Crystals. Polymers-Basel 2010, 2 (4), 766-785; (b) Murugesan, Y. K.; Rey, A. D. Structure and rheology of fiber-laden membranes via integration of nematodynamics and membranodynamics. J Non-Newton Fluid 2010 , $165(1-2), 32-44$

27. Rofouie, P.; Pasini, D.; Rey, A. D., Nanostructured free surfaces in plant-based plywoods driven by chiral capillarity. Colloids and Interface Science Communications 2014, 1, 23-26.

28. Cheong, A. G.; Rey, A. D., Cahn-Hoffman capillarity vector thermodynamics for curved liquid crystal interfaces with applications to fiber instabilities. J Chem Phys 2002, 117 (10), 5062-5071.

29. Rapini, A.; Papoular, M., Distorsion d'une lamelle nématique sous champ magnétique conditions d'ancrage aux parois. J. Phys. (Paris) Colloques 1969, 30 (C4-54).

30. Hoffman, D. W.; Cahn, J. W., Vector Thermodynamics for Anisotropic Surfaces .1. Fundamentals and Application to Plane Surface Junctions. Surf Sci 1972, 31 (1), 368-388.

31. Edwards, D. A.; Shapiro, M.; Brenner, H.; Shapira, M., Dispersion of Inert Solutes in Spatially Periodic, 2-Dimensional Model PorousMedia. Transport Porous Med 1991, 6 (4), 337-358.

32. Outram, B. I.; Elston, S. J., Spontaneous and stable uniform lying helix liquid-crystal alignment. J Appl Phys 2013, 113 (4).

33. Salter, P. S.; Carbone, G.; Jewell, S. A.; Elston, S. J.; Raynes, P., Unwinding of the uniform lying helix structure in cholesteric liquid crystals next to a spatially uniform aligning surface. Phys Rev E 2009, 80 (4).

34. Saupe, A., Disclinations and Properties of Director Field in Nematic and Cholesteric Liquid-Crystals. Mol Cryst Liq Cryst 1973, 21 (3-4), 211-238.

35. Cheong, A. G.; Rey, A. D., Cahn-Hoffman capillarity vector thermodynamics for liquid crystal interfaces. Phys Rev E 2002, 66 (2). 36. Rey, A. D., Mechanical model for anisotropic curved interfaces with applications to surfactant-laden liquid-liquid crystal interfaces. Langmuir 2006, 22 (1), 219-228.

37. (a) Rey, A. D., Nemato-capillarity theory and the orientationinduced Marangoni flow, Liq Cryst 1999, 26 (6), 913-917; (b) Rey, A. D., Marangoni flow in liquid crystal interfaces. J Chem Phys 1999, 110 (19), 9769-9770; (c) Eelkema, R.; Pollard, M. M.; Katsonis, N.; Vicario, J.; Broer, D. J.; Feringa, B. L., Rotational reorganization of doped cholesteric liquid crystalline films. J Am Chem Soc 2006, 128 (44), 14397-14407.

38. (a) Rey, A. D., Generalized cholesteric permeation flows. Phys Rev E 2002, 65 (2); (b) Rey, A. D., Simple shear and small amplitude oscillatory rectilinear shear permeation flows of cholesteric liquid crystals. J Rheol 2002, 46 (1), 225-240; (c) Rey, A. D., Helix uncoiling modes of sheared cholesteric liquid crystals. J Chem Phys 1996, 104 (11), 4343-4346.

39. Doedel, E.; Oldeman, B., Auto-07p: Continuation and Bifurcation Software for Ordinary Differential Equations. 2012

40. Faetti, S.; Palleschi, V., Experimental Investigation of Surface Deformations at the Nematic-Isotropic Interface - a New Method to Measure the Nehring-Saupe Elastic-Constant K-13 (+). J Phys-Paris 1985, 46 (3), 415-424.

41. Manyuhina, O. V., Shaping thin nematic films with competing boundary conditions. The European Physical Journal E 2014, 37, 48-52. 
42. Boudet, A.; Mitov, M.; Bourgerette, C.; Ondarcuhu, T.; Coratger, R., Glassy cholesteric structure: thickness variation induced by electron radiation in transmission electron microscopy investigated by atomic force microscopy. Ultramicroscopy 2001, 88 (4), 219-229.

43. Rey, A. D.; Denn, M. M., Analysis of Transient Periodic Textures in

Nematic Polymers. Liq Cryst 1989, 4 (4), 409-422.

. M. Soft

introduction. Springer: New York, 2003; p xxv, 637 p., 2 p. of plates.

45. Maeda, H., An atomic force microscopy study of ordered molecular assemblies and concentric ring patterns from evaporating droplets of collagen solutions. Langmuir 1999, 15 (24), 8505-8513.

46. Rey, A. D., Polar fluid model of viscoelastic membranes and interfaces. J Colloid Interf Sci 2006, 304 (1), 226-238. 